\title{
Virtual Human Modeling and Simulation for Toll Booth Design in Indonesia
}

\author{
Tegar Septyan ${ }^{\mathrm{a},}$ Boy Nurtjahyo ${ }^{\mathrm{b}}$, \\ ${ }^{1}$ Department of Industrial Engineering, Universitas Indonesia, Indonesia, \\ ${ }^{2}$ Department of Industrial Engineering, Universitas Indonesia, Indonesia \\ tegar.septyan @ui.ac.id ${ }^{a}$, boymoch@eng.ui.ac.id ${ }^{b}$
}

Keywords: Ergonomic,Queuing Theory, Posture Evaluation Index,Configuration,Toll Booth

\begin{abstract}
This research studies the ergonomic aspect from toll booth and operators performance. It is mainly based on working posture and service time of operators. The analysis of working posture based on Posture Evaluation Index using Software Jack 6.1, meanwhile service time based on queuing theory using WinQsb. The output of the study can be divided to actual and 36 reconfiguration design. The results suggest that the most ergonomic design is with $51 \mathrm{~cm}$ in seat height, $5 \mathrm{~cm}$ in foot rest height, and $80 \mathrm{~cm}$ in desk height. Based on simulation, it can reduce the average time of costumer spend in the queue until $82 \%$ from 35.31 seconds to 6.4 seconds.
\end{abstract}

\section{Introduction}

Congestion is one of the main problems on transportation sector in Indonesia, especially happened in toll booth. Congestion in toll booth causes many road users have to wait a long time. One of the factors that affect it, because the toll booth operated in Indonesia generally still used manual systems. Manual systems based on human as the operator for its service, hence human factor becomes important for improving service quality in toll booth.

Unfortunately, the issues about human factors in the design of work systems tend to be ignored. Consequently, it affected most of the workstations not ergonomics. Since the manual system caused work is done manually and repetitive, workstation which is not ergonomics will cause operator fatigue and also decline the performance. Moreover, the toll booth operator is potentially affected by Musculoskeletal Disorder [1] and other discomfort [2]. The risk of physical complaints on toll operators in doing transactions is approximately $21 \%$ [3]. One of the steps that can be done to improve the performance of the toll booth operators and service performance is by developing the work system that focuses on the operator. The work systems development includes the design of an ergonomic workstation for the operator. Consequently, the operator can improve the performance and will not get fatigue easily. In this research, the approach is divided into two main sections: ergonomics and queuing simulation. The main objective of this research is to design toll booth which can increase operators performance.

\section{Methodology}

In this research, the main area is related to virtual/digital human modelling ergonomics [4]. Virtual human modeling (VHM) is ergonomics concept which usually refers to modeling physical aspect of human with main focus on anthropometry and physical strain. We combine VHM with ergonomics approach and queuing simulation in terms of service performance on operator. Ergonomics approach that used in this study is a method of Posture Evaluation Index (PEI) [5]. This method aims to calculate the human posture comfort level that is modeled in the Jack 6.1 and based on Task Analysis Toolkit. Jack Software is designed to model and simulate human interaction with the environment and working tools when analyzing the ergonomics aspects of the model that has been created [6]. Jack is used for digital human modeling in the virtual environment [7]. The analysis results will be used to see conditions of ergonomics postures and their interaction. For the second approach, which based on the simulation of the queue is used to analyze the performance of the operators for the actual conditions and the recommendation condition. 
For data, it can be divided into several types: work design dimension and anthropometry data workers for designing the dimensions of an ergonomic workstation. In addition, it is required data service and inter arrival time of the vehicles that will be analyzed based on queuing theory. After making observations, then conducted a simulation based on virtual human modeling through analysis of PEI (Posture Evaluation Index). PEI is a method for calculating the level of comfort of human postures that are modeled in the software based on the results of Task Jack 6.1 Analysis Toolkits. From the results of this simulation, the ergonomics value will be seen from the actual and reconfiguration design, which indicate how workstations have an effect on the performance of the operator with an indicator of service rate and views based on the queue through the use of simulation software WinQsb.

\subsection{Data Input for Jack Software}

\subsubsection{Actual Dimension}

The data in actual condition include dimension equipment, such as :

- $\quad$ Seat Height

$: 58.5 \mathrm{~cm}$

- Seat Width

$: 39 \mathrm{~cm}$

- Seat Angle

$: 105^{\circ}$

- Table Height

$: 82 \mathrm{~cm}$

- $\quad$ Length of Window

: $60 \mathrm{~cm}$

- Width of Window

: $50 \mathrm{~cm}$

- Window Height from Ground: $83 \mathrm{~cm}$

\subsubsection{Anthropometric Data}

For anthropometric data of operators, sampling was conducted for 57 operators. Sampling was divided into 3 types which based on percentile of 5, 50, and 100. Table 1 shows anthropometric data of operators.

Table.1 Percentile of Operators

\begin{tabular}{|l|l|l|l|}
\hline Percentile & $\mathbf{5}^{\text {th }}$ & 50th & 95th \\
\hline Height $(\mathrm{cm})$ & 162 & 168 & 173.5 \\
\hline Weight $(\mathrm{kg})$ & 54.0 & 62 & 70.3 \\
\hline
\end{tabular}

\subsubsection{Simulation of Movement}

The movement simulated in software Jack 6.1 simulation is divided into several phases as follows:

- Creating a virtual environment

- Creating virtual human model

- Positioning the virtual human model in virtual environment in accordance with the real situation

- Providing assignments or work on a virtual human according to the desired working movement

- Performing verification and validation of the model have been made

- Analyzing the performance of virtual human model by using Task Analysis Toolkit (TAT) which is present on the Jack software. 


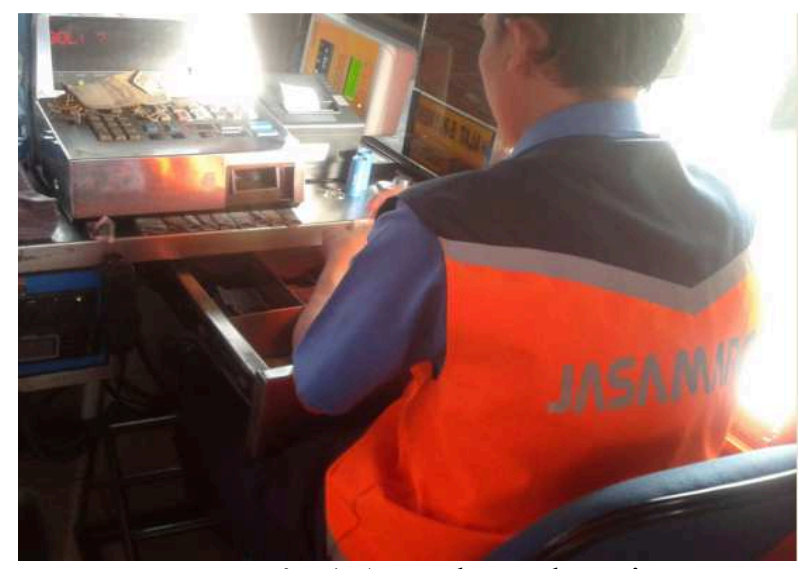

Fig.1 Actual Workstation

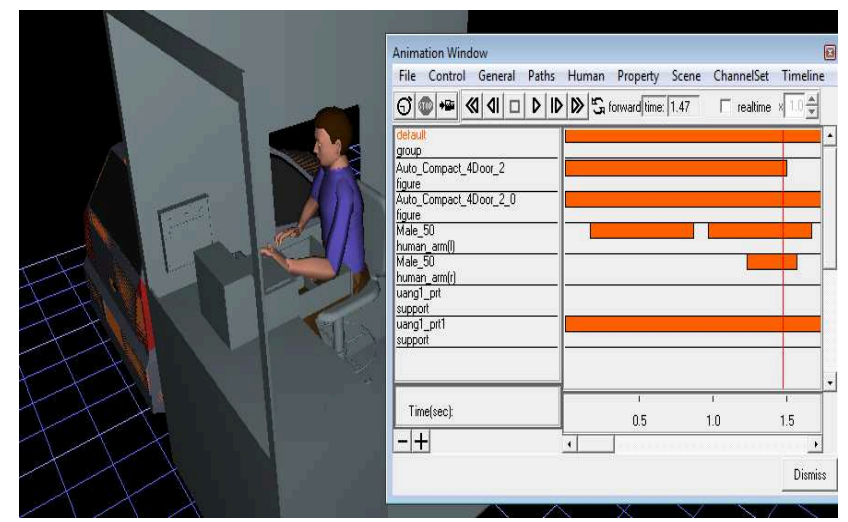

Fig.2 Jack Virtual Environment Simulation

\subsection{Data Input for WinQsb}

Data input for WinQsb based on service time and inter arrival time. For service time data, it is obtained during the time period of 4 hours. For these data, service time is lognormal distributed with a mean of 0.597 . For inter arrival is distributed exponentially with an average of 5,961. From these data and then put on the input column from WinQsb software.

\subsection{Redesign of Configuration}

After testing the design of posture and working methods, then created the design based ergonomic reconfiguration. In the design of a reconfiguration of the design, the components that are designed based on the principle of reconfiguration work such as chairs, desks, and windows. These components are designed based on ergonomic design [8]. For these components is determined based on the principle of anthropometric of the human body. The determination is made based on the minimum and maximum values. After determining the range of values, it choose the exact values for each factor, such as :

- Seat Height (TD): $47 \mathrm{~cm}, 51 \mathrm{~cm}$, and $54 \mathrm{~cm}$

- Seat Angle (KD): 7 degrees

- Backrest Angle (KS): 105 degree

- Seat Width (LD): $44 \mathrm{~cm}$

- Footrest Height (TF): $5 \mathrm{~cm}$ and $10 \mathrm{~cm}$

- Footrest Width (LF): $27 \mathrm{~cm}$

- Armrest Height (TA): $23 \mathrm{~cm}$

- Backrest Height (TSP): $48 \mathrm{~cm}$

- Desk Height (TM): 70, 75 and $80 \mathrm{~cm}$

- Window Width (LJ): $75 \mathrm{~cm}$

- Window Length (PJ): $80 \mathrm{~cm}$
- Window Height from ground: $74 \mathrm{~cm}$ and $78 \mathrm{~cm}$ 
Based on these factors, there are constant factors and changeable factors. The changeable factors are 4 factors, they are seat height, desk height, footrest height, and window height from ground. From these factors, design based on the principle of factorial combinations is created. The design based on level of the factor. For the number of combinations, it was based on the following calculations:

$\begin{array}{ll}\text { Seat Height (TD) } & : 3 \text { levels } \\ \text { Desk Height (TM) } & : 3 \text { levels } \\ \text { High backrest distance (TF) } & : 2 \text { level } \\ \text { Height of Window (TJT) } & : 2 \text { levels }\end{array}$

So, it takes $3 \times 3 \times 2 \times 2=36$ combinations in reconfiguration design. For the 36 reconfiguration design can be seen from the table below :

Table.2 Reconfiguration Design

\begin{tabular}{|l|l|l|l|l|l|l|l|l|l|l|l|l|l|l|}
\hline Config & TD & TM & TF & TJT & Config & TD & TM & TF & TJT & Config & TD & TM & TF & TJT \\
\hline $1 \mathrm{~A}$ & 54 & 80 & 10 & 78 & $2 \mathrm{~A}$ & 51 & 70 & 10 & 74 & $3 \mathrm{~A}$ & 47 & 80 & 5 & 78 \\
\hline $1 \mathrm{~B}$ & 54 & 80 & 5 & 74 & $2 \mathrm{~B}$ & 51 & 80 & 10 & 78 & $3 \mathrm{~B}$ & 47 & 70 & 5 & 78 \\
\hline $1 \mathrm{C}$ & 54 & 70 & 10 & 74 & $2 \mathrm{C}$ & 51 & 80 & 5 & 78 & $3 \mathrm{C}$ & 47 & 80 & 10 & 74 \\
\hline $1 \mathrm{D}$ & 54 & 70 & 5 & 74 & $2 \mathrm{D}$ & 51 & 80 & 5 & 74 & $3 \mathrm{D}$ & 47 & 80 & 5 & 74 \\
\hline $1 \mathrm{E}$ & 54 & 70 & 10 & 78 & $2 \mathrm{E}$ & 51 & 70 & 5 & 74 & $3 \mathrm{E}$ & 47 & 70 & 10 & 78 \\
\hline $1 \mathrm{~F}$ & 54 & 75 & 10 & 74 & $2 \mathrm{~F}$ & 51 & 75 & 5 & 74 & $3 \mathrm{~F}$ & 47 & 70 & 5 & 74 \\
\hline $1 \mathrm{G}$ & 54 & 75 & 5 & 78 & $2 \mathrm{G}$ & 51 & 80 & 10 & 74 & $3 \mathrm{G}$ & 47 & 75 & 5 & 78 \\
\hline $1 \mathrm{H}$ & 54 & 75 & 5 & 74 & $2 \mathrm{H}$ & 51 & 70 & 10 & 78 & $3 \mathrm{H}$ & 47 & 75 & 10 & 74 \\
\hline $1 \mathrm{I}$ & 54 & 70 & 5 & 78 & $2 \mathrm{I}$ & 51 & 75 & 5 & 78 & $3 \mathrm{I}$ & 47 & 80 & 10 & 78 \\
\hline $1 \mathrm{~J}$ & 54 & 80 & 5 & 78 & $2 \mathrm{~J}$ & 51 & 70 & 5 & 78 & $3 \mathrm{~J}$ & 47 & 70 & 10 & 74 \\
\hline $1 \mathrm{~K}$ & 54 & 80 & 10 & 74 & $2 \mathrm{~K}$ & 51 & 75 & 10 & 74 & $3 \mathrm{~K}$ & 47 & 75 & 5 & 74 \\
\hline $1 \mathrm{~L}$ & 54 & 75 & 10 & 78 & $2 \mathrm{~L}$ & 51 & 75 & 10 & 78 & $3 \mathrm{~L}$ & 47 & 75 & 10 & 78 \\
\hline
\end{tabular}

\section{Result and Discussion}

\subsection{Result of Posture Simulation}

In the calculation of PEI, LBA component is important to influence value of PEI. The greatest value of the LBA on $5^{\text {th }}, 50^{\text {th }}$, and $95^{\text {th }}$ percentile at the actual configuration. It indicates the actual configuration have a higher risk of injury than other designs. The smallest LBA at percentile 5 th is happened on $2 \mathrm{C}$ configuration. For percentile 50 and 95 , the smallest value is happened on configuration $2 \mathrm{C}$. It means, workstation on this percentile is better than actual condition.

For the OWAS value, footrest makes the value of a reconfiguration of the OWAS is 1 from 3 for the actual value. It means that footrest reduces complaints. In addition, footrest also make chair more ergonomics.

For the RULA value, the ranges values are between 3 and 5. The highest value is happened on actual configuration, while the smallest value in some reconfiguration designs. The most important part is armrest to support arm and hand in order to prevent a prolonged injury. With conformity with the dimensions of the body size, operator does not need to spend extra effort when reaching the working equipment because its position is relatively closer to the hand.

Based on LBA, OWAS, dan RULA values, PEI can be calculated based on

$$
\mathrm{PEI}=\mathrm{I}_{1}+\mathrm{I}_{2}+\left(\mathrm{mr} . \mathrm{I}_{3}\right)
$$

For:

$\mathrm{I}_{1} \quad=\mathrm{LBA} / 3400 \mathrm{~N}$

$\mathrm{I}_{2} \quad=\mathrm{OWAS} / 4$

$\mathrm{I}_{3} \quad=\mathrm{RULA} / 7$

$\mathrm{mr} \quad=1,42$ 
After calculating PEI values for actual design and 36 combinations of reconfiguration design, we compare the value for each configuration. It aimes to get the optimal configuration which has the lowest of PEI. The lowest value of PEI in design means that it is better in ergonomic aspect than other designs.

From the Fig.3, it can be seen the highest PEI for 5th, 50th, and 95th percentile happened in the actual configuration. It means that the actual configuration of workstation from the toll booth is not ergonomic. For the 5th percentile, the configuration has the lowest value of PEI located on the 3D configuration because it allows more dimension for the 5 percentile. For 50 and 95 percentile, the configuration has the lowest value of PEI is in the configuration of $2 \mathrm{C}$.

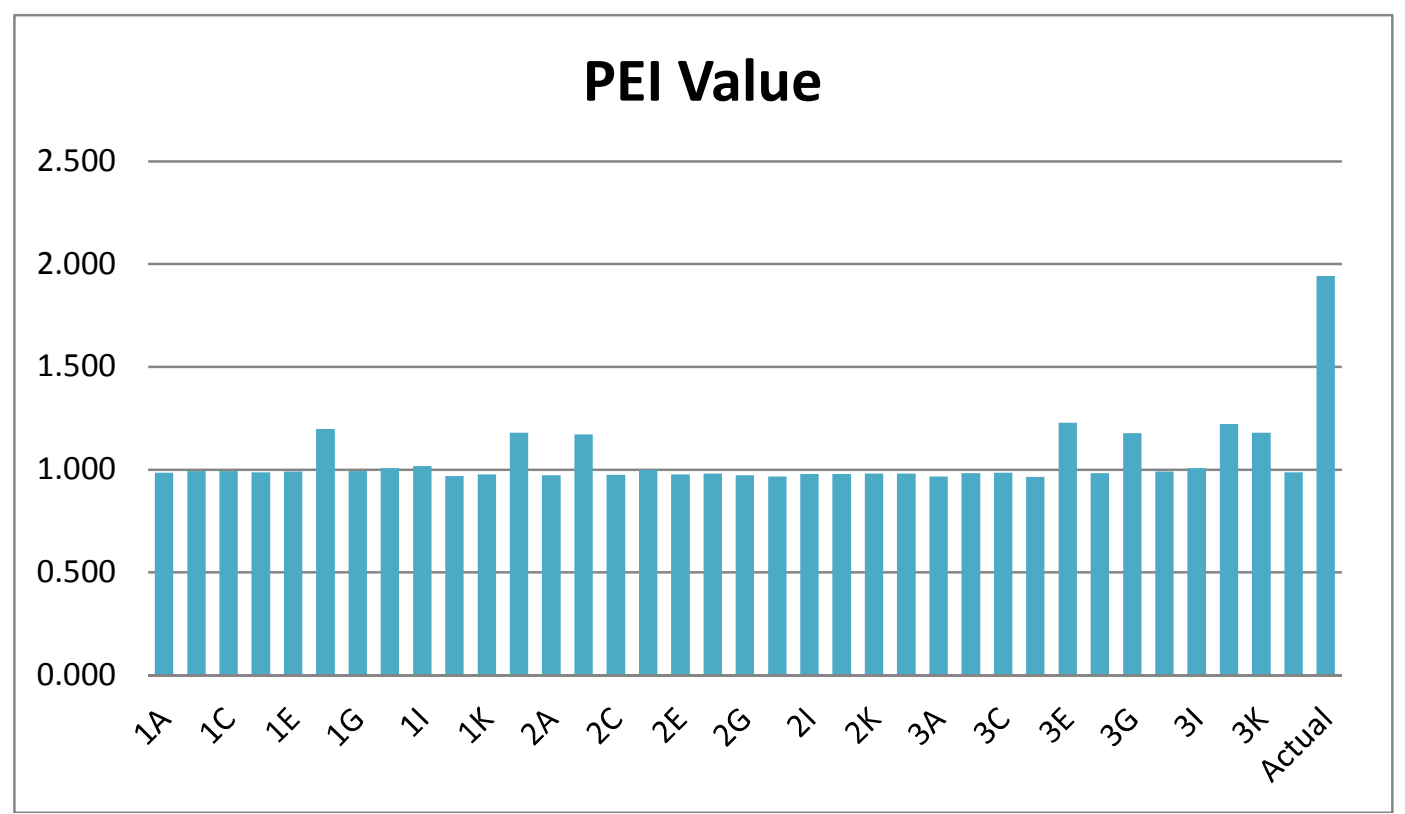

Fig.3 PEI Values

In this research, it also analyzed the result based on factorial design. From R-Square value obtained was of $96.22 \%$, which indicates that the values of PEI from the model are influenced by $96.22 \%$ of the factors in the configuration. While, the rests is influenced by other factors. It can bee seen in Fig 4 and Fig 5.

From the PEI, it choose configuration $2 \mathrm{C}$ that has a combination of factors seat height 51 $\mathrm{cm}$, desk height $80 \mathrm{~cm}$, backrest height $5 \mathrm{~cm}$, and height of the window from ground $78 \mathrm{~cm}$. For the three percentile types of operators, it can decrease the value of PEI more than $49 \%$ for 5 th percentile, and about $50.3 \%$ for $50^{\text {th }}$ and $95^{\text {th }}$ percentile from actual configuration.

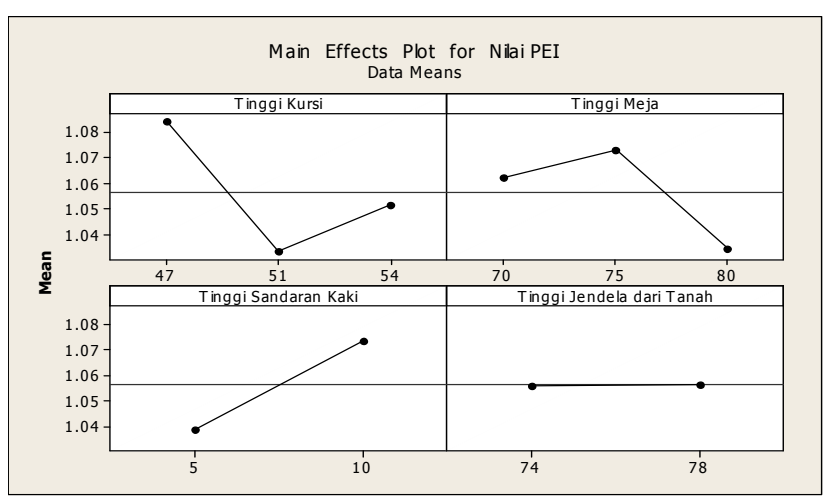

Fig.4 Main Effect Plot

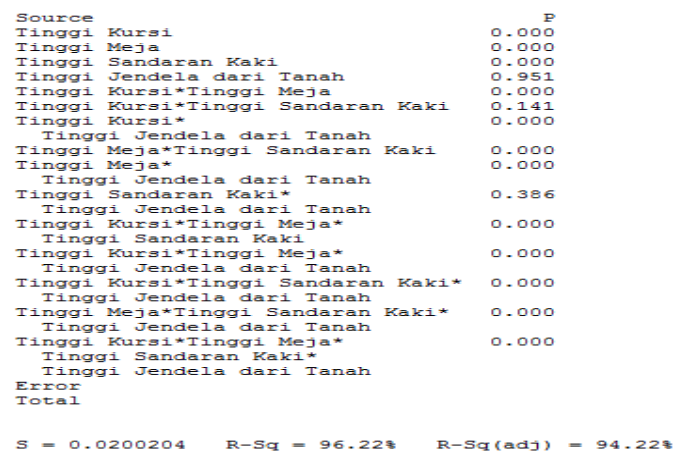

Fig.5 Factorial Design Result 


\subsection{Result of Performance Simulation}

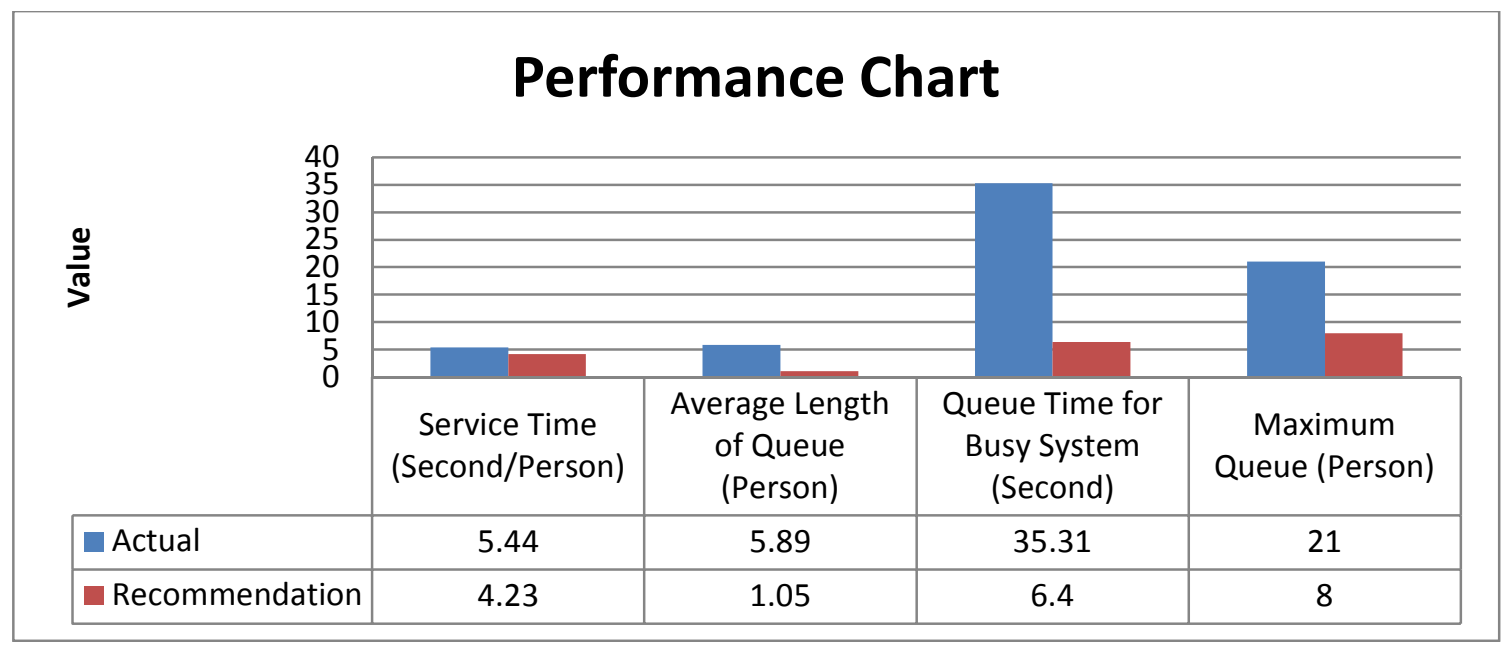

Fig.6 Performance Comparison

From the Fig.6 above, it can be seen that reconfiguration design can reduce time to serve customer. For the actual conditions, time to serve the customer is about 5.44 seconds on average, while for recommendation, the value is 4.23 . It indicates that it decrease $22 \%$ from the actual configuration. For the value of the length of the queue and queue time, it was decreasing of $82 \%$ from the actual configuration. With a new configuration, it will reduce the length and time of queues significantly.

It also decrease $62 \%$ of the time on the toll booth, from 21 to level 8 customers level. From all of this result, it can be seen that redesign configuration can improve the operator performance and decrease the level of the queue.

\section{Conclusion}

For the selection of optimal reconfiguration based on ergonomic and design of factorial, it choose the design configuration $2 \mathrm{C}$ which has lowest value of PEI. In terms of the performance of the service resulting from current conditions based on simulations, it shows the average rate of 5.89 queue of vehicles, with a maximum length of vehicles reach 21 vehicles. For the reconfiguration $2 \mathrm{C}$, it can significantly improve the performance of its services and reduce the queues that occur at the toll booth. It can be seen from a reduction in the time queue on a busy system previously 35.4 seconds to around 4 seconds, as well as reduction in the length of the average queue on a busy system from 5.89 to around 1.05 vehicles. Therefore, based on the reconfiguration of workstations design, it can reduce the risk of work as well as the level of the queue.

\section{References}

[1].P.Strauss, et al. A health survey of toll booth workers. Journal of Safety Research Volume 2 (2002)

[2].Jurum, et al. Ergonomics of Spinal Operational Comfort While Working at Tollbooths (2009)

[3].R.Day, et al. Evaluation of Ergonomic and Security Toll Booth. Research at Worker Compensation Board (1996)

[4]. Bubb, H. Future Application of DHM in ergonomics design. Springer, Heidelberg (2007)

[5].Caputo,F.,Giuseppe Di Girinimo, and Adelaide Marzano. A Structured Approach to Simulate Manufacturing System in Virtual Environment. Italia :University of Naples (2006)

[6]. Siemens PLM Software Inc. Jack task analysis toolkit (TAT) training manual. California: Author (2008)

[7]. Wilson, J.R. Virtual Environments and Applied Ergonomics.” Applied Ergonomics 30 (1999)

[8]. Pheasant, Steven. Bodyspace: anthropometry, ergonomics and the design of work. London: Taylor \& Francis (1997) 